\title{
Technology Enhanced Neuroanatomy Learning during Covid-19 Pandemic - A Questionnaire Based Study from a Teaching Hospital in Mysore, Karnataka, India
}

\author{
Vidya C.S. ${ }^{1}$, Deepa Bhat ${ }^{2}$, Ravishankar Mathada Vamadevaiah ${ }^{3}$ \\ 1,2,3 Department of Anatomy, JSS Medical College, JSS Academy of \\ Higher Education and Research, Mysore, Karnataka, India.
}

\section{ABSTRACT}

\section{BACKGROUND}

The present Covid-19 situation has created an era of learning through the electronic devices, where YouTube channel is playing an important role. Neuroanatomy is a complex subject requiring three-dimensional orientation of the structures. Practical teaching by using the cadaveric specimens is a usual practice, but in the current situation the virtual platform is an indispensable and sustainable option for both teaching and learning activities. In the present study the utility of YouTube and digital content on neuroanatomy was assessed among I MBBS students using selfadministered questionnaire during Covid -19 pandemic.

\section{METHODS}

The questionnaire based cross sectional study of prosected neuroanatomy specimens in the department of Anatomy were utilized to create digital content modules. According to the topics, PDF content was generated, and it was shared before the commencement of virtual class. Later YouTube link was shared with our I MBBS students through social media platforms like WhatsApp and Facebook regularly. At the end of completion of whole teaching schedule, a questionnaire was circulated to obtain the feedback on this teaching method. Finally, the responses were collected and interpreted.

\section{RESULTS}

In the present survey, 257 participants ( 176 females and 81 males) from 10 medical colleges responded to all 12 items of the questionnaire. We observed that $36 \%$ of them graded excellent for content, $25 \%$ for audio quality, $21 \%$ for video quality, 29 $\%$ for specimens used, $25 \%$ for labelling of specimens in YouTube videos. Out of 257 responses $35 \%$ of them were graded excellent for pdf content, $30 \%$ for pictorial representation of brain specimens, $30 \%$ for labelling and $24 \%$ for length. For overall rating for teaching learning method $35 \%$ of them graded $8,17 \%$ graded 9 and $7 \%$ of them have graded 10.

\section{CONCLUSIONS}

This mode of learning can be used for the purpose of distal education as per the convenience of the students, who are presently staying away from the campus. Our students have taken the benefit of teaching where the PDF and YouTube contents were appreciated by large number of students.

\section{KEY WORDS}

Neuroanatomy, YouTube, Digital Content, Technology, Learning Resources
Corresponding Author: Dr. Vidya CS, Professor, Department of Anatomy, JSS Medical College, JSS Academy of Higher Education and Research, Mysore, Karnataka, India. E-mail: vidyacs@jssuni.edu.in

DOI: $10.14260 / \mathrm{jemds} / 2021 / 241$

How to Cite This Article:

Vidya CS, Bhat D, Vamadevaiah RM. Technology enhanced neuroanatomy learning during Covid-19 pandemic - a questionnaire based study from a teaching hospital in Mysore, Karnataka, India. J Evolution Med Dent Sci 2021;10(16):11301134, DOI: 10.14260/jemds/2021/241

Submission 06-12-2020,

Peer Review 19-02-2021,

Acceptance 25-02-2021,

Published 19-04-2021.

Copyright (C) 2021 Vidya C.S. et al. This is an open access article distributed under Creative Commons Attribution License [Attribution 4.0 International (CC BY 4.0)] 


\section{BACKGROUND}

The Covid-19 pandemic has led to closure of educational institutions causing remarkable impact on education. Lockdown has compelled the teachers to instruct through online platform. It has disrupted the academic activities among all professions. Though digital platforms are used for learning, many of them are facing a great challenge to adjust to a sudden change. ${ }^{1}$ Medical education is not an exception to face this challenge. Most of the medical schools have quickly adapted to the online classes by shifting to virtual modes. Various online platforms like ZOOM, web ex, Google classroom, Impart us etc. are utilised by different institutions. Neuro anatomy is a subdivision of anatomy which deals with detailed study of structure of nervous system. Application of neuro anatomy knowledge to clinical practice is perceived to be very significant. But complexity of the subject content, and its 3D orientation makes them difficult to learn, assimilate and recapitulate. It requires a great motivation to keep them interested to learn this area of anatomy. ${ }^{2}$

The intricate structures, with its 3-dimensional relationships, and challenge in clinical integration are cited among the potential causes for difficulty in learning. In the absence of direct contact teaching with faculty, undergraduate neuro anatomy education is vulnerable in the time of the Covid-19 lockdown. ${ }^{3}$ The use of social networks in medical education can remodel and enhance anatomy teaching and learning; one such network is the video-sharing site YouTube. They support independent learning and integration in a problem-based curriculum. ${ }^{4}$ There are various ways that online learning can be structured and implemented. Reinforcement of regular online teaching with any additional methods would supplement the asynchronous learning. The present situation has created an era of learning through the electronic devices where the YouTube channel has become a significant vehicle.

Currently the concept of teaching and learning methods have gone beyond the boards and books, because present day is revolutionized by the technology which can be accessed by each and every student. Electronic or E-learning means learning through internet or intranet connectivity through the electronic gazettes which is one of the important and widely used method of learning in many national and international universities, colleges, institutions, tutorials, learning web portals, etc. around the world. Hence YouTube videos of the relevant structures with additional learning resources were supplemented to routine zoom class teaching of undergraduate neuro anatomy.

The present study aims to assess the utility of YouTube and digital content on Neuroanatomy modules among I MBBS students using self-administered questionnaire during Covid 19 pandemic.

\section{METHODS}

Ethical clearance was obtained from institute ethical committee. Questionnaire based cross sectional study was done between May 2020 and July 2020 during Covid pandemic, period. Routine online classes for I MBBS students were conducted in Department of Anatomy, JSS Medical
College, and Mysore. The neuro anatomy classes were conducted under 10 modules, covering all the parts of neuro anatomy as per the syllabus.

The prosected specimens available at dissection theatre were demonstrated through video recording, which is synchronizing with the theoretical explanations. The recorded video was peer reviewed by subject experts, later it was edited and quality of audio and video were checked before uploading on the YouTube channel. Supplementary PDF study material and YouTube link of dissection videos were shared among students belongs to other colleges as well through the WhatsApp and Facebook groups. After a gap of 15 days of online teaching schedule, a 12-item expert validated questionnaire was utilised to obtain feedback on this teaching method. The responses were subjected to statistical analysis, and the results were interpreted.

All the 12 items were assessed (Table 1) and lst the responses were subjected to statistical analysis, and the results were interpreted.

\begin{tabular}{|c|c|c|}
\hline Sl. No. & Items & Grade \\
\hline 1 & $\begin{array}{c}\text { Overall score for YouTube videos } \\
\text { a. Content } \\
\begin{array}{cl}\text { b. } & \text { Audio quality } \\
\text { c. } & \text { Video quality } \\
\text { d. } & \text { Specimens used } \\
& \text { e. Labelling } \\
\text { f. } & \text { Length / duration }\end{array}\end{array}$ & $\begin{array}{c}1-4 \\
\text { 1. Below average, 2. Average } 3 . \\
\text { Good 4. Excellent }\end{array}$ \\
\hline 2 & $\begin{array}{l}\text { Overall score for PDF study material } \\
\text { a. Content } \\
\text { b. Pictorial representation } \\
\text { c. Labelling } \\
\text { d. Length / duration }\end{array}$ & $\begin{array}{l}\text { 1. Below average, } 2 \text {. Average } 3 . \\
\text { Good 4. Excellent }\end{array}$ \\
\hline 3 & $\begin{array}{l}\text { I would prefer a. YouTube videos b. PDF c. } \\
\text { YouTube + PDF }\end{array}$ & $\mathrm{a} / \mathrm{b} / \mathrm{c}$ \\
\hline 4 & $\begin{array}{l}\text { Would you prefer to use videos and PDF? } \\
\text { a. Pre class } \\
\text { b. Post class }\end{array}$ & $\mathrm{a} / \mathrm{b}$ \\
\hline 5 & $\begin{array}{l}\text { Can this YouTube / PDF content be utilised } \\
\text { for learning clinical or } \\
\text { applied anatomy }\end{array}$ & Yes / No \\
\hline 6 & $\begin{array}{c}\text { Were the handwritten diagrams in PDF } \\
\text { reproducible? }\end{array}$ & Yes / No \\
\hline 7 & $\begin{array}{l}\text { Will the videos / PDF help in quick revision } \\
\text { for assessment }\end{array}$ & Yes / No \\
\hline 8 & $\begin{array}{l}\text { Do you feel that YouTube videos assist to } \\
\text { connect and relate anatomy learning than } \\
\text { power point presentation alone }\end{array}$ & Yes / No \\
\hline 9 & $\begin{array}{l}\text { How often do you watch YouTube videos? } \\
\text { a. Everyday b. Every week c. Never }\end{array}$ & Answer \\
\hline 10 & $\begin{array}{l}\text { Overall rating for this teaching and learning } \\
\text { mode }\end{array}$ & $\begin{array}{c}1-10 \\
1 \text { - least, } 10 \text { - maximum }\end{array}$ \\
\hline 11 & Any suggestions for further improvement & Answer \\
\hline 12 & $\begin{array}{l}\text { Do you prefer to have more videos in } \\
\text { future in other topics in anatomy }\end{array}$ & Yes / No \\
\hline \multicolumn{3}{|c|}{$\begin{array}{c}\text { Table 1. Questionnaire on Digital Content } \\
\text { and YouTube Videos of Brain Specimens }\end{array}$} \\
\hline
\end{tabular}

\section{Statistical Analysis}

All the responses were subjected to statistical analysis, and the results were interpreted. Frequency of responses were expressed in percentage.

\section{RESULTS}

In the present survey 257 participants (176 females and 81 males) from 10 Medical Colleges responded to all 12 items of the questionnaire. We observed that $36 \%$ of them graded excellent for content, $25 \%$ for audio quality, $21 \%$ for video 
quality, $29 \%$ for specimens used and $25 \%$ for labelling of specimens in YouTube videos as shown in Figure 1.
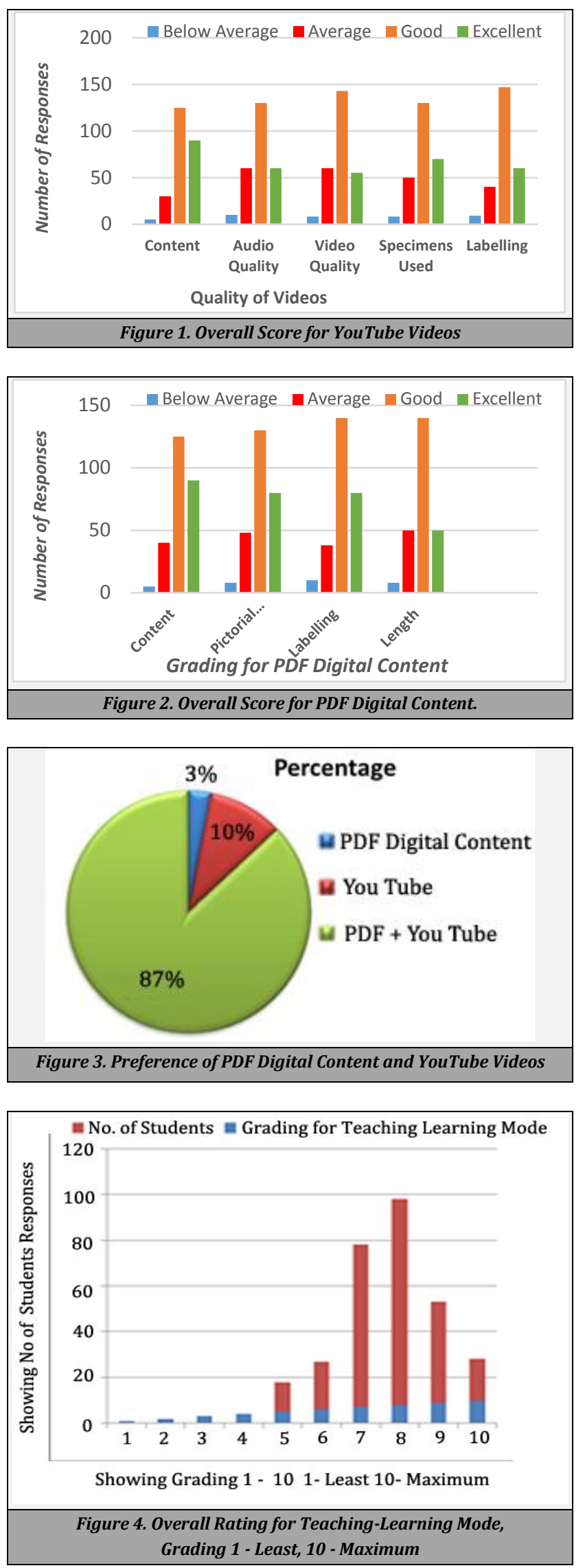

Out of 257 responses $35 \%$ of them graded excellent for pdf content, $30 \%$ for pictorial representation of brain specimens,
$30 \%$ for labelling and $24 \%$ for length (Figure 2). 223 participants preferred both pdf and YouTube videos for selfdirected learning (Figure 3). $72 \%$ of students preferred Neuroanatomy videos and PDF access before the class and 28 $\%$ of students preferred in post class. $84 \%$ of students responded positively that YouTube, and PDF content could be utilized for learning clinical or applied anatomy. $67 \%$ of students responded that handwritten diagrams in PDF content were reproducible. $92 \%$ of students responded that videos and PDF will help in quick revision for assessment and helps to score better marks. $76 \%$ students opined that YouTube videos could assist to relate anatomy learning than power point presentation alone. $82 \%$ of students preferred to have videos in other topics in Anatomy.

In overall rating for teaching learning method, $35 \%$ of them graded $8,17 \%$ graded 9 and $7 \%$ of them have graded 10 (Figure 4). Most of the students suggested that practical exposure was necessary as only videos alone would not be fully sufficient for learning. But this resource or supplementary material was a good asset for students that can be utilised for learning.

\section{DISCUSSION}

YouTube platform is one of the largest video sharing and learning virtual platform that not only caters to entertainment but also for an efficient delivery of teaching and learning across disciplines. It is one of the accessible and convenient alternate sources of learning to explore the concepts especially during the current critical pandemic lockdown situation, the students could access the learning material from the home at their convenience. Dr. Najeeb's virtual online YouTube lectures stand as a best illustration which is widely accepted by number of students around the world. Today teaching is supplemented with the power point presentations (PPT), animations, videos, smart board usage, etc. Its utility has enhanced the subject understanding by influencing more clarity on the concepts. Advent in the field of information science and technology has enabled us to extend the education through outreach programmes globally. It has influenced every field including medical education. We the medical teachers need to transform from the conventional and traditional teaching methods to virtual platforms, where the actual human involvement was playing an important role, but it was associated with the requirement of lot of manpower to cater to its need. Electronic mode of teaching can be delivered as a live transmission or it can be recorded well in advance; it can be released on the net for its access all around the world. Use of live video lectures and demos along with pre and post lecture assignments made a great impact on student learning and evaluation. The live online teaching is having an opportunity to dialogue with the students which mutually influence the interest in teaching and learning. Online teaching may require a pre and post session activities; it is having an advantage of monitoring at the end.

Study conducted by Ayman, a questionnaire survey on perception of YouTube videos in learning anatomy on Jordanian Medical Students was conducted. They reported that $79.1 \%$ of the students used YouTube for learning gross anatomy, dissection videos were the most frequently viewed 
anatomy related content. YouTube offered them as a most convenient, cost-effective, and anatomical supplementary tool supporting their subject understanding. ${ }^{5} \mathrm{~A}$ comparative study by Rocio including the $3^{\text {rd }}$ year volunteer medical students who were learning radiology practical lessons through 3D virtual classroom v / s real world classroom, were assessed for their pre and post training knowledge in the taught subject. They reported similarity in acquisition in their interpretive skill on the radiology findings. The virtual classrooms facilitated an added advantage of free participation among the students without the fear of identity disclosure. ${ }^{6}$ In the present survey virtual learning of neuroanatomy module through YouTube and PDF together was appreciated by $87 \%$ of students, but only $10 \%$ of them appreciated YouTube videos alone. A study conducted in King Abdul-Aziz University, Saudi Arabia, in a circumstance where there was not enough number of teaching faculties were available for the conventional teaching, where virtual classroom was an inevitable option. A comparative study which was conducted to assess the outcome of live conventional face-to-face classroom teaching $\mathrm{v} / \mathrm{s}$ E-learning classroom teaching. In both these modules, face-to-face and virtual classes were conducted by the same instructor to compare the outcome between these two groups and reported that not much difference in response among the learners from either of these two groups. ${ }^{7}$ Though the final year medical students have expressed their positive opinion about the virtual learning platforms, but it has failed to compensate their practical skill component, which can create an obvious deficit in fulfilling their clinical competency. ${ }^{8}$ Though E learning is not able to see its complete replacement to didactic conventional lectures, but in the present inevitable situation creating a barrier for students to attend their regular institutionalized academic activities where E-platform seems to be an indispensable option. In the present study overall acceptance of Neuroanatomy virtual teaching and learning module under "Likert's scaling has indicated an excellent score grade. In the present critical pandemic situation, virtual platform can foster an attitude of self-directed learning among the fraternity of medical students particularly during their preclinical learning activities. ${ }^{9}$

No platform can fulfil the complete academic requirement at any point of time. Despite having number of advantages and some limitations, the live online teaching is having an opportunity to have a dialogue with the students, which mutually influence the interest in teaching and learning between the teacher and student.10 Online teaching may require pre and post session activities to monitor the outcome at the end. The other advantages of E-learning are, its ease to access to an unconditional learning, it is a cost-effective educational resource, it can target specific and needful audiences, it offers a combination of acquiring the education along with work during their course, which is a common practice in western countries, and it mainly provides barrier less educational approach worldwide. Some of its limitations are including, difficulty to understand the student involvement under online learning due to lack of personal contact between the teacher and students. ${ }^{11}$ The learning through the electronic media requires a basic expertise to handle the devices. The smart phones or android phones, advancement in optic fiber technology has revolutionized the accessibility of internet services to wider extent. They have a great potential in mediating the learning especially in the field of medical education, where its application can access the required information on the spot; its justified usage has influenced the teaching and learning activities despite some technical drawbacks. Present Covid-19 pandemic situation, where webbased learning has created huge market for the industry stake holders for providing proper learning resources, materials, contents, etc. which can be accessed tirelessly through different apps.

However, from the teaching and learning point of view, there are number of constraints to give a complete and satisfactory practical hand on exposure to the students of medical fraternity which still remains as a challenge in the present situation.

\section{CONCLUSIONS}

The present pandemic situation has given rise to a need for an alternate tool for asynchronous learning through media like YouTube. Despite a number of drawbacks, E-learning has emerged as a best alternate tool. Supplementing learning resources through the digital content would exponentially enhance the student learning. Our education system needs to imbibe technology to cope up with the changing needs of global educational standards, where one can access learning materials from the nook and corner of the world. YouTube is a powerful tool in this regard, in the current situation.

\section{Limitations}

Technical constraints and technical snag can disturb the learning sessions. Above all, the most difficult task to conduct the practical classes, especially in the field of medicine is that the students may fail to realize the importance of human touch, pain, and psychology of the patient.

Data sharing statement provided by the authors is available with the full text of this article at jemds.com.

Financial or other competing interests: None.

Disclosure forms provided by the authors are available with the full text of this article at jemds.com.

\section{REFERENCES}

[1] Kapasia N, Paul P, Roy A, et al. Impact of lockdown on learning status of undergraduate and postgraduate students during Covid-19 pandemic in West Bengal, India. Child Youth Serv Rev 2020;116:105194.

[2] Martin K, Bessell NJ, Scholten I. The perceived importance of anatomy and neuroanatomy in the practice of speechlanguage pathology. Anat Sci Educ 2014;7(1):28-37.

[3] Hall S, Border S. Online neuroanatomy education and its role during the coronavirus disease 2019 (Covid-19) lockdown. World Neurosurg 2020;139:628.

[4] Jaffar AA. YouTube: an emerging tool in anatomy education. Anat Sci Educ 2012;5(3):158-64. 
[5] Mustafa AG, Taha NR, Alshboul OA, et al. Using YouTube to learn anatomy: perspectives of Jordanian medical students. Biomed Res Int 2020;2020:6861416.

[6] Lorenzo-Alvarez R, Rudolphi-Solero T, Ruiz-Gomez MJ, et al. Medical student education for abdominal radiographs in a $3 \mathrm{~d}$ virtual classroom versus traditional classroom: a randomized controlled trial. AJR Am J Roentgenol 2019;213(3):644-50.

[7] Al-Nuaim HA. The use of virtual classrooms in e- learning: a case study in King Abdulaziz University, Saudi Arabia. E-Learning and Digital Media 2012;9(2):211-22.

[8] Novintan S, Mann S, Hazemi-Jebelli Y. Simulations and virtual learning supporting clinical education during the
Covid-19 pandemic. Advances in Medical Education and Practice 2020;11:649-50.

[9] Huynh R. The role of e-learning in medical education. Acad Med 2017;92(4):430.

[10] Gaikwad A, Randhir VS. E-learning in India: wheel of change. International Journal of e- Education, e-Business, e-Management and e- Learning (IJEEEE) 2016;6(1):40-5.

[11] Abou El-Seoud MM, Taj-Eddin IATF, Seddiek N, et al. Elearning and students' motivation: a research study on the effect of e-learning on higher education. International Journal of Emerging Technologies in Learning (IJETL) 2014;9(4):20-6. 